\title{
Research on the Influence of Web Celebrity Anchors on Consumers' Willingness to Buy
}

\author{
Shuhua Wu ${ }^{1}$, Lina Fang, * \\ ${ }^{1}$ School of Business Administration, Liaoning University of Science and Technology, Liaoning, 114000, China \\ * Corresponding author: Lina Fang (Email: 442754168@qq.com)
}

\begin{abstract}
With the development of the Internet, how to use network broadcasting to effectively promote to enhance consumers' willingness to buy has become a major challenge for enterprises. This paper takes the relevant characteristics of web celebrity anchor as the research object, uses econometric theory, uses literature analysis method and empirical research method, puts forward the corresponding research assumptions, and constructs a logical model of the impact of web celebrity live broadcast on consumers' willingness to buy. This paper is mainly based on the live Taobao data in the gray dolphin data, with empirical analysis through factor analysis and regression analysis method. The results found that the number of thumb up, rising fans and the number of viewers showed a positive impact on sales. In view of this conclusion, corresponding measures are put forward to improve the purchase willingness of consumers in the broadcast studio and promote the rapid maturity of Taobao live broadcast marketing.
\end{abstract}

Keywords: Web celebrity anchor, Broadcast room, Willingness to buy.

\section{Foreword}

Due to the epidemic in 2020 , webcast is accepted by the public as a new shopping model. At the same time, various industries are also competing to use webcast to promote the promotion of enterprise products or services. Li Jiaqi sold five and a half hours of Taobao live 23,000 orders, completed 3.53 million volume, 267 million, more than one million viewers, and can not grab goods in a second slow... Such live broadcast goods can completely subvert the sales volume of traditional business model and become the hottest business model at present. Many industries in online marketing, publicity products, sales realization and so on give priority to online live broadcasting. The so-called web celebrity anchor is based on the network platform, which attracts a large number of netizen with their expertise and has a certain impact on their fans.

It is precisely because of the development of Internet technology, the opening of network platforms, the increase of Internet users and many other factors that promote the development of web celebrity anchors. From the perspective of the development process of web celebrity red, BBB 1 has mainly experienced three eras: the first is the 1.0 era formed with excellent writing skills or strange expression, the second is the 2.0 era formed with excellent pictures or unexpected writing style, and the third is the 3.0 era of publishing diversified styles in the form of video. The development of web celebrity in different stages presents distinct characteristics, especially to the development of the 3.0 era, and Internet platforms can attract more consumers, so as to increase the probability of purchase willingness to achieve. At present, web celebrity is in the era of web celebrity 3.0, and all walks of life have emerged $\mathrm{BBB} 1$, thanks to the continuous iterative innovation of the Internet, the rise of various Internet live broadcast platforms and the fact that Internet users have more channels to interact with with BBB 1 [1]. Obviously, the urgent practical problem is to find which factors influence web celebrity anchors 'willingness to buy and how enterprises should use the huge energy of BBB 1 anchors to improve the transaction rate of enterprises' products or services.

Although the development of web celebrity live broadcasting has been for a long time, the academic theoretical research on online live broadcasting is still not comprehensive. Web celebrity anchors in the era of 3.0 mainly share daily life, life experience and product grass planting to fans in the form of short videos [2], Among them, the biggest feature with the previous web celebrity era is the two-way interaction between anchors and fans [3]. So in order to comprehensively study how web celebrity anchor is to influence consumer willingness to buy, the academic research mainly includes information acquisition, website beautification, consumer behavior and use motivation, although also studied the characteristics of web celebrity anchor, development process and communication role, interaction with fans and the consumer purchase will, brand influence, emotional integration, brand image, trust mechanism, etc., but little literature to discuss web celebrity to buy influence mechanism.

Therefore, the significance of studying the influence mechanism of web celebrity anchors on consumer purchase willingness is of the following significance. First, web celebrity anchor to further enrich and develop the relevant theories of web celebrity anchor and network marketing; second, analyze the impact of different anchor characteristics on consumer willingness to buy, can provide merchants to choose suitable web celebrity anchor for this product; third, study the impact of web celebrity red anchor personal characteristics on consumer willingness to buy, can help web celebrity anchors to further refine the path to improve consumers to purchase hospitals.

\section{Literature Review}

broadcast at home and abroad, the research content mainly focuses on the current status of online live broadcast, network marketing, consumer behavior and consumer purchase willingness, among which the most research is consumer behavior. Shi Zhen and Zhu Xiyong (2021) analyzed the 
current situation of network broadcast, studied the different types and existing problems in network broadcast, and finally proposed that the future network broadcast should develop in the direction of precision, customization, personalized, intelligent, specialization and standardization [4]. Wang Runjin (2020) conducts characteristic analysis, content analysis and mode analysis of Taobao live broadcast from the perspective of network marketing, and puts forward four specific implementation opinions on the future development of Taobao live broadcast, first, the market positioning, find the target population; second, encourage more people to participate in live broadcast; the rich innovation of form and content; and the fourth to improve the idea and taste of Taobao live content [5]. Huang Sihao, Deng Fumin (2021) and so on believe that consumers 'impulse purchase in live broadcast scenes is the key to marketing success. They use fine processing possibility model to find that platform characteristics and personal characteristics of anchors are positively promoting consumer immersive experience and satisfaction, and consumers' immersive experience and satisfaction further lead to impulse purchase desire [6]. Liao Wenhu (2021) from the characteristics of live shopping, study the impact of interactive, vivid, entertainment on consumer distrust, the results found that vivid, entertainment are positively affect the emotional presence, scene and cognitive presence, only interactive positive affect emotion, scene, and emotional presence negative affect consumer distrust. It pointed out that the live streaming platform should strengthen the interaction with consumers, and enhance the vividness and entertainment of the platform itself [7].

By combing the literature, it can be found that scholars usually use the theories of sociology, communication and economics on their personal characteristics and evolution, role and interaction in the economy. On the role of the anchors in the network economy, it mainly includes the influence of consumer purchase intention, brand influence, emotional integration, brand image and trust mechanism. It can be seen that the academic research of network live broadcasting and web celebrity anchors is mainly due to the development of Internet technology, the change of business model and the rise of web celebrity BB 1 related anchors. Web celebrity anchor is mainly through the Internet network to share their own life fun, shopping experience, product evaluation, experience sharing and other personal knowledge and attract the attention of netizen, effective interaction and influence fans, but few existing literature on different web celebrity anchor how to influence fans purchase willingness to explore, live platform web celebrity anchor through what factors to improve consumers to buy products not sufficient theoretical explanation. Therefore, this study is planned to be broadcast from different web celebrity BBB 1 anchors, and based on the differences of BBB 1 anchors, to discuss the influence mechanism of different BBB 1 anchors on consumers' purchase willingness on online platforms, in order to effectively use the personal characteristics of different BBB 1 anchors to improve product sales performance.

\section{Study Hypotheses and Data Sources}

Web celebrity anchors not only the popularity of commodity spokesmen, but also their own characteristics, product intake and innovative characteristics. First of all, many scholars in the existing literature have defined the characteristics of web celebrity live broadcast. Kong Ruilin (2021) believes that web celebrity anchors are not limited to any career. Based on the network platform, people who are known, concerned about and spread by a large number of netizens with their personal talent, appearance, ideas are network anchor[8].Zhang Mingming (2021) believes that those who have unique personal charm, characteristics or talents, receive more network attention and accumulate fans on the Internet, and use their own traffic to sell goods are the network anchor [9]. Yang Nan (2021) believes that web celebrity anchors refers to real-time interaction with the audience with the help of live broadcast platform. While transmitting product information and product image, they can enhance the audience's trust in the product, and then affect consumers' brand attitude towards [10]. It can be seen that web celebrity anchors, like celebrity endorsements, both rely on their own strong influence to influence consumer behavior and enhance consumers' willingness to buy. However, compared with celebrities, web celebrity anchors are closer to ordinary people, and can introduce comprehensive details of commodity details to consumers. On the basis of previous research, Meng Lu and others compared the characteristics of live web celebrity and traditional endorsement celebrities, and subdivided web celebrit1 into entertainment, skill and cargo according to the characteristics of live broadcast content [2]. Web celebrities in live broadcast platforms are somewhat different from endorsement stars in the traditional sense. endorsement stars usually use the popularity or halo effect of stars to market consumers, consumers chase and trust stars, but also trust the products they endorse, and have the desire to buy [11].

Online live broadcast has great advantages compared with commercial spokesmen. The biggest difference between web celebrity anchors and endorsement stars is that their ability to interact with consumers in two ways. web celebrity anchors can convey different information such as experience and details of products or services in enterprises to consumers in detail [12], Close the distance with consumers, and consumers 'questions about products or services can also be timely answered, which can enhance consumers' willingness to buy. Therefore, this article divides the influence of web celebrity anchor on consumers' purchase willingness into four dimensions: basic (number of fans, number of thumb up number, comments number, powder increase number), traffic (number of views, number of views, number of store entering number, number of stores), sales (number of goods, live broadcast time).

Different enterprises choose different marketing methods at different stages, but most enterprises will choose star endorsement. Star endorsement usually opens the product or service sales market quickly with the popularity of stars, and bundles the star image with enterprise products [13]. However, this bundling means that consumers' willingness to buy is based on their favorite stars. Consumers can not have a comprehensive understanding of the products or services of the enterprise, and it is difficult to establish corporate loyalty, and even once the star image is damaged or the corporate star endorsement is changed. Studies have shown that the product involvement of stars has a positive impact on consumers' brand attitude and willingness to buy [14], However, the biggest drawback of star endorsement is that stars only participate in the product display link, and can not give consumers the communication of product professional knowledge. Therefore, there are a lot of businesses will choose suitable for their products or service opinion leaders to promote, this marketing method does not rely on a body 
but by the product or service itself to attract consumers, mainly because the opinion leaders of products or service have comprehensive and accurate information, have professional knowledge of the industry, and their own products can form objective opinions or Suggestions [15].Web celebrity anchors are more professional than celebrities and more famous than opinion leaders, which is a combination of the two advantages. They can not only convince consumers with knowledge professionalism and accuracy in the network platform, influence consumers through live broadcast skills, and heavily influence the community member with a higher voice [16], It can also be timely two-way interaction with consumers, shorten the distance between consumers, produce a sense of intimacy and then maintain consumer loyalty. To sum up, web celebrity anchors combine the characteristics of stars and opinion leaders to stimulate consumers' willingness to buy to a greater extent. Therefore, this article puts forward the following assumptions:

H1: The more fans the number of web celebrity anchors, the more conducive to promote fans' willingness to buy.

$\mathrm{H} 2$ : The more the number of thumb up of web celebrity anchors, the more conducive to promoting fans' willingness to buy.

H3: The more the comments of web celebrity anchors, the more conducive to promote fans' willingness to buy.

H4: The more the number of web celebrity anchors, the more conducive to promoting fans' willingness to buy.

H5: The more web celebrity anchors watch, the more conducive to promote fans' willingness to buy.

H6: The more watched the number of web celebrity anchors, the more conducive to promote fans' willingness to buy.

H7: The more times the web celebrity anchor enters the store, the more conducive to promoting fans' willingness to buy.

H8: The more the number of web celebrity anchors, the more conducive to promoting fans' willingness to buy.

H9: The more the number of web celebrity anchors, the more conducive to promoting fans' willingness to buy.

H10: The longer web celebrity anchors are, the more conducive to promote fans' willingness to buy.

Because the live data on Taobao cannot be directly obtained by individuals, the gray dolphin data website is now used to obtain the required data resources, which is an analysis tool for the data quoted by $36 \mathrm{Kr}$, Tencent Technology and Burning Finance, which has relatively high credibility. The obtained resources were collated and filtered, summarized and subjected for empirical analysis.

\section{Results and Analysis}

Because 10 variables are selected, there may be multiple collinear problems among each other, this paper adopts the gradual multiple regression to analyze the linear relationship between each variable, comprehensively analyze the impact of each variable on sales, and establishes the following model:

$$
\begin{gathered}
\mathrm{Y}=\alpha 0+\alpha 1 \mathrm{X} 1+\alpha 2 \mathrm{X} 2+\alpha 3 \mathrm{X} 3+\alpha 4 \mathrm{X} 4+\alpha 5 \mathrm{X} 5+\alpha 6 \mathrm{X} 6+\alpha 7 \mathrm{X} 7+\alpha \\
8 \mathrm{X} 8+\alpha 9 \mathrm{X} 9+\alpha 10 \mathrm{X} 10+\mathrm{ei}
\end{gathered}
$$

Among them, $\alpha 1 \sim \alpha 10$ are parameters to be estimated; $\alpha 0$ is constant; ei is error; X1 X10 represents the number of fans, thumb up, comments, fans, views, views, visits, stores, stores, goods and duration of web celebrity respectively. Multiple regression analysis was performed using Eviews7.0 software to increase X 1 to X 10 to the model (1).

With the gradual entry of each variable dimension, its $R$ (decision coefficient) and the adjusted $\mathrm{R}$ party (correction determination coefficient) have all changed, and the model fit is better $(\mathrm{R}>0.4)$, which shows that the model construction is reasonable. It can be seen that the variables respectively $\mathrm{X} 2$, $\mathrm{X} 6, \mathrm{X} 10, \mathrm{X} 4$ are the optimal model. The coefficient of stepwise multiple regression analysis was derived, whose final standardized model is as follows:

$$
Y=6408.608+23.173 X 2+10677.27 X 4+525.474 X 6-588.93 X 10
$$

According to the multiple regression equation model (2), the number of fans, comments, number of views, number of stores, number of stores and goods of web celebrity anchors do not have a very significant impact on the sales of the broadcast room. However, the number of thumb up, powder increase, viewers and duration had a significant impact on its sales. It can be seen that the number of likes in the studio increased by 23.173 units, 1 units increase, sales increased by 10677.27 units. Each unit increase, sales increased by 525.474 units, but the length of each unit increase, sales decreased by 588.93 units. In comparison, the number of powder increases and duration have a greater impact on sales.

\section{Conclusion}

This paper uses the help of gray dolphin data to count the sales volume of different web celebrity anchors in the Taobao broadcast room, and empirically studies the sales volume with 10 variables of fans, thumb up number, comments, powder increase, viewing number, viewing number, store number, number of entering the store, the number of goods, and time length. The following conclusions come from the study:

Through the multiple regression model, shows that thumb up, fans, viewing and time impact on its significant, and likes, fans and viewers show positive effect on sales, and fans, comments, views, into the store, into the store, the number of goods on sales is not very significant.

Based on the above conclusion, the article puts forward suggested measures to improve taobao studio sales: first, the two return to thumb up and number of viewers have a positive impact on sales, so to strengthen the focus of the emergence of "social" mode, platform merchants to take various measures to increase the number of fans, interactive frequency, user guidance, gather attention, increase thumb up and viewers, especially to buy consumers, research the most suitable for consumers, rather than blindly pursue long live broadcast.

\section{Acknowledgment}

Research project of Education Department of Liaoning Province: The impact of consumer behavior on the quality decision of agricultural supply chain 2019LNJC22.

\section{References}

[1] Sun Jing, Wang Xinxin.Web celebrity and web celebrity economy - based on celebrity theory [J].Foreign Economy and Management, 2019 (4): 18-30.

[2] Meng Lu, Liu Fengjun, Chen Syun, et al.Can I evoke you the influence of different types of live web celebrity 
information source characteristics on consumers' willingness to buy mechanism research [J].Nankai Management Review, 2020 (1): 131-143.

[3] Yang Jianghua.From Internet popularity to web celebrity economy: generative logic and evolution process [J].Sociological Review, 2018 (5): 13-27.

[4] Shi Zhen, I wish you Xiyong.Research on the Current Situation and Marketing Development of E-commerce Live Broadcast [J].Operation and Management, 2021 (05): 48-52.

[5] Wang Runjin.Research on Online Marketing Strategy Based on Taobao Live Broadcast [J].Modern Trade Industry, 2020,41 (30): 51-52.

[6] Huang Sihao, Deng Fumin, Xiao Jincen._- is based on the two-path influence perspective [J].Financial Sciences, 2021 (05): 119-132.

[7] Liao Wenhu.Study on the Effect of webcast Shopping Characteristics on Consumer Distrust [J].China Prices, 2021 (04): 109-112.

[8] Kong Rui-ling.The Business Model and Development Prospect of Nethong Economy under the background of "Internet +" [J].Business Economy, 2021 (03): 143-146 + 158.

[9] Zhang Mingming.The dynamic relationship between web celebrity brand IP marketing, consumption psychology and consumption will [J].Business Economy Research, 2021 (05): 83-85.
[10] Yang Nan.Research on the influence mechanism of web celebrity live streaming with goods on consumer brand attitude [J].Journal of the Central University of Finance and Economics, 2021 (02): 118-128.

[11] Zheng Wencong.The characteristics of "3.0" web celebrity and audience psychology [J].New Media Research, 2016 (6): 1415.

[12] LEE E, OVERBY J.Creating value for online shoppers: implications for satisfaction and loyalty[J].Journal of Consumer Satisfaction, 2004(5): 54-67.

[13] Zhou Yanfeng, Zhang Ting, Chen Shaona._ takes the web celebrity brand "Xi Tea" as an example [J].Business Economy and Management, 2018 (4): 70-80.

[14] GRANT M.Who is the celebrity endorser? cultural foundations of the endorsement process[J].Journal of Consumer Research, 1989(3): 310-321.

[15] Zhao Dawei, Feng Jiaxin.Research on the Impact of Key Opinion Leaders of E-commerce Anors on Consumer Purchase [J].Business Research, 2021 (04): 1-9.

[16] Ding Hanqing, Wang Yaping.Analysis of the "opinion leader" characteristics in SNS cyberspace 36 Take Douban network as an example [J].News and Communication Research, 2010 (3): 82-91

[17] Zhang Hongxia, Liu Xiaonan.Research on advertising spokesperson participation: deep endorsement or shallow endorsement? [J].Psychology Journal, 2010 (5): 587-598. 